\title{
Research on the structure of values of 6-7 years old children
}

\author{
Alla Osipova ${ }^{1, *}$, Victoria Boguslavskaya ${ }^{1}$, Anna Vlasova $^{1}$, and Ivan Borodin ${ }^{1}$ \\ ${ }^{1}$ Southern Federal University, Rostov-on-Don, 344006, Russia
}

\begin{abstract}
The article presents the results of the study of the value structure of 6-7 years old children. The relevance of the study is caused by the role that childhood has on subsequent human development. The basic values that determine human development are formed at the age of 7 years. However, the study of the value sphere of children presents a number of difficulties - the limited methods and techniques that allow us to explore the value sphere of children, the closeness of the family for scientific research, the insufficient social experience of the child himself, differences in the level of communicative development of children and a number of other difficulties and restrictions. At the same time, the use of various research methods - projective, standardized, observations provides empirical data on the structure of values of 6-7 years old children. Both projective and standardized techniques were used in the study. The results show that the development of the value sphere in children 6-7 occurs very unevenly: from complete amorphism to the presence of a clear hierarchical structure. There are confirmed differences in the structure of preferred values among boys and girls. Girls aged 6-7 choose values related to the communicative sphere, while boys of this age are guided by values that are active character.
\end{abstract}

\section{Introduction}

The value-meaning sphere of personality is quite actively studied both in Russian and foreign psychological science. The psychological aspects of the meaning sphere of personality, the features, functions and factors determining its development are presented in the works of L. S. Vygotsky, A. N. Leontiev, B. G. Ananyev, B. S. Bratusya, A. G. Asmolov, V. V. Stolin, D. A. Leontiev, V. A. Yadov, F. e. Despite the wide interest in studying the meaning sphere of a person's personality, in psychological science there is a terminological uncertainty of the corresponding conceptual apparatus, the mechanisms and factors of the formation, development and functioning of the meaning sphere are not sufficiently studied (Kurilenko, 2014).

The value-meaning sphere is a qualitative system-forming characteristic of the personality, therefore, the process of forming values, the result of this process determines the direction of personal development. According to such researchers as M.S. Yanitsky and A.V. Gray, the value-meaning sphere sets the parameters of personal development

\footnotetext{
*Corresponding author: aaosipova@sfedu.ru
} 
(Yanitsky, Gray, 2012).

The development of personality in ontogenesis is determined by a whole range of factors. A child from the moment of his birth falls into the world of human relations. During the growing up period, the meaningful characteristics of the child's place in the relationship system are complicated and filled with new components. The child has more opportunities for knowledge, new meanings, while new responsibilities arise. For the development of the child, it is of great importance how he feels in the system of relations with significant adults, what the system poses to him, what exactly he observes in the reality significant to him. As a result, he picks up the main components of this system of relations, not adapting, but becoming an active participant during adulthood. (Friesen, Kostenko, 2018).

At the age of 6-7 years, the conditions created by adults for the formation of the valuemeaning sphere of the personality acquire special significance. Such conditions include the formation of value relations to oneself (the formation of a positive self-concept) and the environment. As O.G. Kholodkova notes, "these relationships are characterized by a positive emotional attitude of children towards a close or adult, which is reinforced by an adult and transformed into a desire for moral actions. It is on the basis of the formation of a value attitude towards oneself and relatives that the child develops value guidelines, moral motives and builds a positive self-concept "(Kholodkova, Turnaeva, 2016). Thus, in preschool age, the foundations of the value-meaning sphere of the personality are formed. (Evdokimova, 2018).

The purpose of our study was to study the structure of values of children 6-7 years old. The methodological basis of the study was: the cultural and historical theory of L.S. Vygotsky (the principle of cultural polling of the psyche, behavior, consciousness); a meaningful concept and general psychological theories describing the dynamics of meaning development (I.V. Abakumova, A.G. Asmolov, V.K. Vilyunas, I.V. Dubrovina, V.V. Stolin, V.S. Mukhina, E.V. Subbotsky); the concept of values and personal meanings of A.N. Leontyev, D.A. Leontyev; a meaningful concept and general psychological theories describing the dynamics of meaning development (I.V. Abakumova, A.G. Asmolov, V.K. Vilyunas, I.V. Dubrovina, V.V. Stolin, V.S. Mukhina, E.V. Subbotsky).

\section{Materials and Methods}

The study involved 114 children of 6-7 years old with normal physical development. The age of the children surveyed was 6 years 3 months to 7 years 2 months (the average age of the children was 6 years 7 months). 58 boys and 56 girls were present in the study sample. All children live in Rostov-on-Don, attend kindergarten No. 286. The study of the structure of values of children 6-7 years old was carried out using such methods as the projective methodology "Houses" (O.A. Orekhova), the methodology "Comprehensive study of selfesteem and value orientations" (I.P. Shakhova), the methodology "Research of value orientations of preschoolers" (S.M. Valyavko, E.V. Averyanova).

\section{Results}

During the specially organized research procedure, we studied the values and value relations of children 6-7 years old to the most important social categories, as well as to activities. To study the peculiarities of the child's value preferences and his activity orientations, we used the projective method "Houses" (Orekhova, 2010), which is similar to the method "Test of color symbolism" (Oboe, Matsioka, 1956). The procedure was carried out in a group of 5-6 children, using the following materials: response form and color 
pencils of eight colors (red, blue, yellow, green, purple, brown, gray, black). Identical pencils painted in appropriate colors were used. The study consisted of three painting tasks. In the first task, the child was asked to arrange colors depending on the color preference. In the second task, it was proposed to paint houses in which such feelings live: happiness, grief, justice, resentment, friendship, quarrel, kindness, anger, boredom, admiration. In the third task, it was proposed to paint houses in which you can do something special: draw, sing, do mathematics, read, play, walk, communicate with loved ones, dance, engage in physical education. Painting the last house, the child himself decided what he would like to do.

As a result of the study, we can note that children most often chose the value of "happiness" (5.9 points). In second place is the value of "kindness" (4.9 points), in third place is the value of "friendship," and then "justice" (4.4 points). At the same time, it should be noted that in the studied sample, children prioritized the studied social categories differently. The ranking of values in the study sample is shown in Table 1.

Table 1. Ranking of values in a sample of children 6-7 years old.

\begin{tabular}{|c|c|c|c|c|}
\hline № & Value & $\begin{array}{c}\text { Very } \\
\text { important } \\
(\mathbf{1 - 3} \text { choices })\end{array}$ & $\begin{array}{c}\text { Important } \\
\mathbf{( 4 - 6} \text { choices })\end{array}$ & $\begin{array}{c}\text { No matter } \\
\mathbf{( 7 - 8} \text { choices })\end{array}$ \\
\hline 1 & Happiness & $65 \%$ & $29 \%$ & $6 \%$ \\
\hline 2 & Boredom & $54 \%$ & $29 \%$ & $17 \%$ \\
\hline 3 & Kindness & $45 \%$ & $35 \%$ & $20 \%$ \\
\hline 4 & Friendship & $37 \%$ & $43 \%$ & $20 \%$ \\
\hline 5 & Quarrel & $29 \%$ & $36 \%$ & $35 \%$ \\
\hline 6 & Grief & $33 \%$ & $39 \%$ & $28 \%$ \\
\hline 7 & Justice & $31 \%$ & $46 \%$ & $23 \%$ \\
\hline 8 & Grievance & $31 \%$ & $44 \%$ & $25 \%$ \\
\hline 9 & Rage & $29 \%$ & $37 \%$ & $34 \%$ \\
\hline 10 & Admiration & $27 \%$ & $37 \%$ & $36 \%$ \\
\hline
\end{tabular}

As can be seen from table 1, the largest number of children (65\%) chose "happiness" as the most important value, but $6 \%$ of children noted this category as unimportant. The value of "kindness" prevails as the most important in $45 \%$ of children, while $37 \%$ of respondents consider "friendship" to be the main value. The value of "justice" was chosen as a very important $31 \%$ of children, while $23 \%$ of children do not consider this value important. An analysis of preferred direct activities showed that the most preferred activity in children 6-7 years old is drawing, which is noted by children much more often than activities such as "communication with loved ones" and "play." Perhaps drawing allows a child to express himself and his emotions in the absence of fear of being misunderstood by others, while the child does not need to make efforts to organize communication, such as in a game or dance.

We used the methodology "Study of the Value Orientations of Preschool Children" by S.M. Valyavko, E.V. Averyanova to study the values of children 6-7 years old (Valyavko, Averyanova, 2012). The study of the values of the child according to this method was carried out strictly individually. Ten black and white photos were posted alternately in front of the child, these photos were with the image of certain objects: vitamins, videos, doll, knight, book, disc, candy, phone, microphone, icon. A certain image of the object corresponded to a certain value. The psychologist clarified whether the child correctly perceives the object depicted in the photo: "Name what is depicted here." Further, the psychologist suggested to the child: "Choose what you like most" - and postponed the photo chosen by the child; then repeated the instruction and postponed the next photo chosen by the child, continuing until all the photos had ended. As a result of the study, a list of values arranged by degree of importance is obtained. The generalized data for the entire sample are presented in Table 2. 
Table 2. Ranked list of values of children 6-7 years old (methodology S.M. Valyavko. E.V. Averyanova).

\begin{tabular}{|c|c|c|c|c|c|}
\hline № & Values & $\begin{array}{c}\text { Average } \\
\text { value }\end{array}$ & Dispersion & Mode & Median \\
\hline 1 & Communication & 6.4 & 6.3 & 9 & 8 \\
\hline 2 & Hedonism & 5.65 & 7.2 & 5 & 5 \\
\hline 3 & Health & 5.5 & 7.54 & 7 & 6 \\
\hline 4 & Spiritual value & 5.5 & 8.9 & 3 & 5.5 \\
\hline 5 & Cognition & 4.9 & 5.8 & 4 & 5 \\
\hline 6 & Game & 4.4 & 10.8 & 1 & 4 \\
\hline
\end{tabular}

The study showed that the value most often chosen by children is the value of "communication" (6.4 points). In the methodology, this value is represented by photos of the phone and microphone. Perhaps the process of digitalization of society contributes to the fact that a modern child of 6-7 years is fluent in the skills of using various gadgets and communication for children occurs not only directly, in the real world, but also indirectly, through the use of the Internet and various social networks. In second place in terms of frequency of choice is the value of "hedonism" (5.6 points), according to a number of authors, hedonism is characteristic of children of this age and its vivid manifestation at this age is the norm. "Spiritual" value and "health" value (5.5 points each) are in third place in the ranking of selected values. It should be noted that in half of cases, children found it difficult to identify a card depicting an icon. Taking into account the reaction of surprise and questions, it could be concluded that children saw the image of the icon for the first time, which can be explained by the fact that the Russian state is secular, and as the experience of this study showed, not every family discusses issues of religion. At the same time, children who know about the meaning of the icon showed emotions of delight and awe at the appearance of the image of the icon and in six cases the words of prayer were heard.

We can note the fact that children are much less likely to choose such values as "cognition" (4.9 points) and "game" (4.43 points). It should be noted that $55 \%$ of respondents chose the value of "communication" as very important, and only $21 \%$ put it in the last places. Among the respondents, 54\% put the value of the "game" only 7-10 choices, presenting it as unimportant. The value of "cognition" is 7-10 choices in $47 \%$ of preschoolers, and the value of "health" is defined as unimportant in $43 \%$ of children. However, in the study sample there are children who have a different value hierarchy. In particular, $28 \%$ of children still identified the "game" as a very important value, $21 \%$ of children put "cognition" in 1st-3rd place, which indicates the importance of this value. Spiritual value was chosen as an important $31 \%$ of children. Perhaps this situation is due to the high motivation of children to enter school, the early conduct of educational classes in preparation for school. The results are shown in Table 3.

Table 3. Ranking of values according to the methodology S.M. Valyavko, E.V. Averyanova in the studied sample of children 6-7 years old.

\begin{tabular}{|c|c|c|c|c|}
\hline № & Values & $\begin{array}{c}\text { Very important } \\
(\mathbf{1 - 3} \text { choices })\end{array}$ & $\begin{array}{c}\text { Important } \\
(\mathbf{4 - 6} \text { choices })\end{array}$ & $\begin{array}{c}\text { No matter } \\
\text { (7-10 choices) }\end{array}$ \\
\hline 1 & Communication & $55 \%$ & $24 \%$ & $21 \%$ \\
\hline 2 & Hedonism & $24 \%$ & $37 \%$ & $39 \%$ \\
\hline 3 & Health & $23 \%$ & $34 \%$ & $43 \%$ \\
\hline 4 & Spiritual value & $31 \%$ & $28 \%$ & $41 \%$ \\
\hline 5 & Cognition & $21 \%$ & $32 \%$ & $47 \%$ \\
\hline
\end{tabular}




\begin{tabular}{|c|c|c|c|c|}
\hline 6 & Game & $28 \%$ & $18 \%$ & $54 \%$ \\
\hline
\end{tabular}

Analysis of the obtained data suggests that two subgroups of children with different value structure were distinguished in the study sample: in one subgroup of children 6-7 years old there is a high rank of the value of "communication," but the general structure of values in children of this subgroup is very amorphous, while in the second subgroup of children there is a clear value-meaning hierarchy with priority of spiritual values, values health and knowledge.

The application of the methodology I.P. Shakhova made it possible to obtain data on the value orientations of children 6-7 years old (Shakhova, 1998). The survey was conducted individually. The child was asked to consider a card with an image of three identical people. The psychologist asked the child: "Here are three very similar boys (girls). This boy is smart, this boy is strong, this boy is healthy. In all other things, they are no different. Which of these boys (girls) would you most like to be? "The result of the answer was entered in a special form. Further, the child was asked to make a choice regarding such qualities as: smart, strong, sociable, well engaged, beautiful, healthy, fun.

The results obtained indicate that the most chosen value is the value "fun" (3.6 points), the next in the ranking of selected values is the value "smart" ( 3.3 points), then "learn well" (3.1 points) and "healthy" (3.1 points). The lowest number of points received such values as "beautiful" (2.9 points), "strong" (2.9 points) and "sociable" (2.6 points). Also often, children chose such a quality as "being fun," accordingly commenting on their choice with the goal of "liking the rest," while much less often choosing the quality - "sociable." We can assume that children 6-7 years old are more focused on assessing themselves from others, thereby a high level of choice of such qualities as "fun" and "smart" implies recognition from others. The implementation of actions that promote communication by children is not considered. It should be noted that in almost a third of subjects $(32 \%)$, the value of "smart" is predominant, in $29 \%$ of children the most important is the value of " learn well " as a prerequisite for successful schooling.

We conducted a comparative analysis of the features of the value and meaning sphere among boys and girls. The results according to the «Houses» methodology indicate that in girls the most important value is "happiness" (5.9 points), in subsequent places there are such values as "kindness" (4.8 points), "friendship" (4.6 points) and "justice" (4.5 points).

Boys also have in the first place the value of "happiness" (5.9 points), but in the second place is the value of "friendship" (4.7) points, followed by such values as "kindness" (5.1 points) and "justice" (4.1 points).

The most significant activity of the girl is considered "singing" (5.6 points) and "game" (5.5) points, as well as "communication" (5.4 points and), drawing (5.3 points). The least preferred activity for girls is "physical education" (3.2 points).

The most preferred activity in boys is "drawing" (5.9 points) and "singing" (5.3 points), then - "scoring" and "physical education" (5 points), "walking in nature" (4.9 points). Next in the ranking are "game" (4.3 points) and "communication" (4.3 points), "reading" (3.9 points). The least preferred activity for boys is "dancing" ( 2.8 points).

We investigated the differences in choices between boys and girls, namely the possible effect of sex on the preferred value or activity by single-factor variance analysis, the results of which are presented in Table 4.

Table 4. Results of sigle-factor variance analysis.

\begin{tabular}{|c|c|c|c|}
\hline № & Activity & F & Significance value \\
\hline 1 & Reading & 4.350 & .039 \\
\hline 2 & Game & 10.868 & .001 \\
\hline 3 & Dances & 55.629 & .001 \\
\hline 4 & Physical education & 19.759 & .001 \\
\hline
\end{tabular}


The most preferred activity for girls is play, for boys - physical education, while girls significantly more often than boys choose dancing and reading as a significant activity. The results of the study on the values of boys and girls on the methodology S.M. Valyavko, E.V. Averyanova are presented in Table 5.

Table 5. Ranked lists of values for girls and boys 6-7 years old on the methodology S.M. Valyavko, E.V. Averyanova.

\begin{tabular}{|c|c|c|c|c|}
\hline № & Girls Values & $\begin{array}{c}\text { Average } \\
\text { Score }\end{array}$ & Boys Values & $\begin{array}{c}\text { Average } \\
\text { Score }\end{array}$ \\
\hline 1 & Communication & 6.4 & Communication & 6.6 \\
\hline 2 & Game & 6.4 & Health & 6 \\
\hline 3 & Spiritual value & 6 & Hedonism & 5.7 \\
\hline 4 & Hedonism & 5.6 & Game & 5.4 \\
\hline 5 & Cognition & 4.7 & Cognition & 5.2 \\
\hline 6 & Health & 4.1 & Spiritual value & 5.1 \\
\hline
\end{tabular}

Girls most often choose "game" (6.4 points) and "communication" (6.4 points) as significant value. In second place is "spiritual value" ( 6 points). Further in the value rating is "hedonism" (5.6 points), "cognition" (4.7 points) and in last place "health" (4.1 points). For boys, the most important value is "communication" (6.6 points), in second place is "health" (6 points), "hedonism" (5.7 points). Less important for boys were the "game" (5.4 points), "cognition" (5.2 points). The last choice was most often the value of "spiritual" (5.1 points). As a result of one-factor variance analysis, where gender acted as a factor, we received reliably significant differences in the following values: game, health, communication (see Table 6).

Table 6. Results of sigle-factor variance analysis.

\begin{tabular}{|c|c|c|}
\hline Value & F & Significance value \\
\hline Game & 12.941 & .001 \\
\hline Health & 14.021 & .001 \\
\hline Communication & 7.983 & .006 \\
\hline
\end{tabular}

Girls are reliably more likely to choose the value of "game," while boys are reliably more likely to choose the value of "communication" and "health."

The results of the study of the values of boys and girls according to the methodology of I.P. Shakhova are presented in Table 7.

Table 7. The results of the study of the values of boys and girls 6-7 years old (methodology I.P. Shakhova).

\begin{tabular}{|c|c|c|c|c|}
\hline № & Girls' Values & $\begin{array}{c}\text { Average } \\
\text { Score }\end{array}$ & Boys' Values & $\begin{array}{c}\text { Average } \\
\text { Score }\end{array}$ \\
\hline 1 & Fun & 4.2 & Strong & 4.3 \\
\hline 2 & Smart & 4.1 & Fun & 3.1 \\
\hline 3 & Beautiful & 3.4 & Healthy & 3 \\
\hline 4 & Learning Well & 3.4 & Learning Well & 2.8 \\
\hline 5 & Healthy & 3.3 & Smart & 2.5 \\
\hline 6 & Sociable & 2.8 & Beautiful & 2.5 \\
\hline 7 & Strong & 1.3 & Sociable & 2.4 \\
\hline
\end{tabular}

Analysis of the data obtained using the methodology I.P. Shakhova allows us to conclude that girls much more often chose such qualities as "fun" (4.2 points) and "smart" (4.1 points) as priorities, the next most important qualities were "learning well" (3.4 points), "beautiful" (3.4 points), "healthy" (3.3 points). The least preferred qualities are "sociable" (2.8 points) and "strong" (1.3 points). 
Boys significantly more often chose such qualities as "strong" (4.3 points), "fun" (3.1 points) and "healthy" ( 3 points). Further in the ranking of elections for boys - "beautiful" (2.5 points), "smart" ( 2.5 points). The most common quality was "sociable" ( 2.4 points).

The results of the univariate variance analysis showed statistically significant differences in the selectable qualities according to sex (see Table 8).

Table 8. Results of sigle-factor variance analysis.

\begin{tabular}{|c|c|c|}
\hline Values & F & Significance value \\
\hline Smart & 14.638 & .001 \\
\hline Strong & 46.973 & .001 \\
\hline Beautiful & 6.305 & .013 \\
\hline Fun & 8.445 & .004 \\
\hline
\end{tabular}

The results show that girls significantly more often than boys choose the values of "smart," "beautiful," "fun," while for boys the most important of the presented value characteristics is "strong."

\section{Discussion}

In Russian psychological science, values are studied as an integral element of personal development. Personality is studied in the context of the social environment, and values are considered as a characteristic of a social subject, co-operating his life experience, while the category "value" is considered in various contexts: socially significant, as personally significant, as semantic constructs. Values act as decisive nodal concepts of the valuesense system, while value orientations determine the attitude of a person to a specific object based on the structure of his personal value-meaning system (Goeke-Morey, Cummings 2017; Sapsağlam, 2017). Values initially determine the value relations and value orientations of the person, fill them with meaning. Personal values imply not only the formulation of personal preferences as a fact, but also the awareness of oneself by the person in value, a kind of "fitting" the value on oneself and the answer to the question, but as a person in this value, whether it is suitable, how to act in this system and whether this system is optimally suitable for the person.(Dering, 2010; Günindi, 2015). The answers to all these questions are contained within the education "value." According to S.O. Elishev, values cannot exist separately from each other and always form a holistic system of values. The foundation of this system S.O. Elishev sees moral values as regulators of personal relations with the outside world (Elishev, 2011). E.M. Vechkanova, following D.A. Leontiev, notes the value-meaning sphere as having the most important function of regulating the entire system of human relations with the world (Vechkanova, 2015).

We consider the value-meaning sphere as a single holistic system, having a complex structure, consisting of many elements connected to each other. This system is inextricably connected with personality, implemented by making personal decisions and activities (Malti, Dys, 2018; Camras, 2017) The value-meaning sphere is a dynamic system that has been formed over many years and is constantly changing and improving throughout a person's life. The development of the value-meaning sphere is a deep intraspersonal process, the essence of which, as noted by E.Yu. Pochtareva, consists "in the person-sense definition of himself in various contexts of behavior, activity, interaction and in the integration of these ideas into a single value-sense space of life" (Postareva, 2017).

Under the influence of the value-meaning sphere, self-perception, self-wear and selfesteem of the personality are formed (Louca-Papaleontiou, 2019). The value-meaning sphere also influences the formation of a picture of the world, determines the choice of important future spheres of activity, directions of the individual's life path. The valuemeaning sphere is a qualitative systemic characteristic of the personality, therefore, the 
process of forming values, the result of this process determines the direction of personal development and the main choices that the personality makes during adulthood and in adulthood. The process of growing up and personality formation is long-term and uneven. To date, many periodizations of mental, personal and social development are known in science: the periodization of L. S. Vygotsky, J. Piazh, L. Kolberg, D. B. Elkonin, E. Erikson, V. I. Slobodchikov, A. V. Petrovsky and a number of other authors (Maralov, 2015).

In our study, we rely on the periodization of the mental development of D.B. Elkonin, according to which each age period is characterized by personality neoplasms, which distinguishes these periods from each other. The driving force of change is the child's leading activity at a specific stage of ontogenesis. Ontogenesis can be represented as an objectively carried out, complex organized process of individual development, including, in particular, the accumulation of neoplasms, the change of leading activity, a change in its content, structure and characteristics of individuals. Both lines of ontogenesis - selfdevelopment and self-realization - are manifested in activity (Derkach, Saiko, 2008).

A child from the moment of his birth falls into the world of human relations. Of great importance is how exactly he feels in the system of relations with significant adults, what the system poses to him, what exactly he observes in reality significant to him. As a result, he picks up the main components of this relationship system, not adapting, but becoming an active participant during adulthood (Karabanova, 2019; Saguilyan, 2018).

At different stages of ontogenesis, the meaningful characteristic of the child's place in the relationship system changes, is complicated and filled with new components. The child has more opportunities for knowledge, new meanings, while new responsibilities arise. This social component is important for the development of the individual as a whole in terms of the activity approach of personal development. The awareness of oneself as a subject of action at an early age develops into a new level of self-consciousness in a senior preschool into the awareness of oneself as a subject in the system of human relations, the bearer of social. This process L.I. Bozhovich connects with the design of a new central to the personality growths, which is designated by her as an "internal position," reflecting the child's self-perception and attitude to himself and her position in life (Suvorova, 2011).

During this period, social consciousness is formed, the child perceives himself as a member of society, reproduces the roles of other members in the game. During this period of ontogenesis, the child, together with a social role, perceives the values broadcast by society (Del, Giudice, 2019; Waller, Hyde, 2018). His perception expands from the intrafamily circle to a wider society (Spinrad, Gal, 2018, Akman, 2011). By the time the preschool age is completed, as L.I. Bozhovich notes, it is possible to trace the child's desire for a new situation in the system of public relations and for a new socially significant activity. The child seeks to fulfill tasks and get the approval of a significant adult, there is an active formation of a new position - the future student. In the modern world, preparation for schooling is actively practiced precisely during preschool childhood, when children are actually set as a schoolboy, successfully fulfill tasks, and do homework. This feature of the education system currently allows you to start the processes of growing up and moving to a new stage of development earlier than it was a few decades ago (Schiller, Bryant, 2009; Ülavare, Veisson, 2015). Children learn writing and reading skills earlier and faster, perceive the importance of completing tasks, learn a new role as a student of the school, accept new requirements for them of the elders and take responsibility. And the phase of development that in the 60-70s of the last century was characteristic of children 7-8 years old, today shifts to an earlier age of 6-7 years. The age of 6-7 years requires special attention from adults who can and should create the necessary conditions for the formation of stable moral forms of behavior, which serve as prerequisites for the development of the value-meaning sphere of the personality (Kholodkova, Turnaeva, 2016). 


\section{Conclusions}

Our research has led to the following conclusions:

1. In children aged 6-7 years, the value sphere can have both an amorphous and a very structured appearance, which indicates the active formation of the value sphere at a given age.

2. The structure of values in boys and girls aged 6-7 years has significant differences.

3. Girls aged 6-7 choose values related to the communicative sphere, while boys of this age are more guided by values that are active in nature.

\section{References}

1. B. Akman, Values Education in Preschool (Anadolu University Web-Offset Facility, Eskişehir, 2011)

2. L.A. Camras, A.G. Halberstadt, Current Opinion in Psychology 17, 113-117 (2017) doi: 10.1016/j.copsyc.2017.07.003

3. M. Del Giudice, Current Opinion in Psychology 25, 1-5 (2019) doi: 10.1016/j.copsyc.2018.02.004

4. A.A. Derkach, E.V. Saiko, The world of psychology 2(54), 193-205 (2008)

5. A.K. Dering, Journal of Psycho educational Assessment 6(28), 564-577 (2010) doi: $10.1177 / 0734282909357151$

6. S.O. Elishev, Values and meanings 2(11), 82-96 (2011)

7. T.G. Evdokimov, Bulletin of the RSUH. Series "Philosophy. Sociology. Art criticism" 1(11), 65-75 (2018)

8. M.A. Friesen, L.O. Kostenko, Bulletin of Kemerovo State University 3, 140-152 (2018)

9. M.C. Goeke-Morey, M.E. Cummings, Current Opinion in Psychology 15, 7-12 (2017) doi: 10.1016/j.copsyc.2017.02.006

10. Y. Günindi, International Electronic Journal of Elementary Education 7(3), 371-382 (2015)

11. O.A. Karabanova, National Psychological Journal 3(35), 71-79 (2019) doi: $10.11621 / \mathrm{npj} .2019 .0308$

12. O.G. Kholodkova, A.A. Turnaeva, Bulletin of the South Ural State Humanitarian and Pedagogical University 4, 139-144 (2016)

13. Yu.A. Kurilenko, Psychopedagology in law enforcement 2(57), 20-23 (2014)

14. E. Louca-Papaleontiou, New Ideas in Psychology 54, 56-62 (2019) doi: 10.1016/j.newideapsych.2019.01.005

15. T. Malti, S.P. Dys, Current Opinion in Psychology 20, 45-49 (2018) doi: 10.1016/j.copsyc.2017.07.036

16. V.G. Maralov, Bulletin of Cherepovets State University 4, 147-152 (2015)

17. O.A. Orekhova, Methods for diagnosing the differentiation of the emotional sphere of a child "Little Houses" (IMATON, St. Petersburg, 2010)

18. E.Yu. Postareva, Bulletin of Perm University. Philosophy. Psychology. Sociology 4, 563-575 (2017)

19. E.M. Sagilyan, Bulletin of the University of the Russian Academy of Education 1, 28$31(2018)$ 
20. Ö. Sapsağlam, Education and Science 89, 87-303 (2017) doi: 10.11114/jets.v6i11.3531

21. P. Schiller, T. Bryant, Teaching 16 basic values to young children (Studium Publishing House, Tartu, 2009)

22. I.P. Shakhova, Workshop on laboratory work of the course "Developmental Psychology" (Institute of Practical Psychology, Moscow, 1998)

23. T.L. Spinrad, D.E. Gal, Current Opinion in Psychology 20, 40-44 (2018) doi: 10.1016/j.copsyc.2017.08.004

24. O.V. Suvorova, News of the Samara Scientific Center of the Russian Academy of Sciences 2(13), 1416-1421 (2011)

25. P. Ülavare, M. Veisson, Journal of Teacher Education for Sustainability 2(17), 108124 (2015) doi: 10.1515/jtes-2015-0014

26. S.M. Valyavko, E.V. Averyanova, Experimental psychology 2(5), 83-95 (2012)

27. E.M. Vechkanova, Modern research on social problems 3(47), 61-75 (2015)

28. R. Waller, L.W. Hyde, Current Opinion in Psychology 20, 11-16 (2018) doi: 10.1016/j.copsyc.2017.07.037

29. M.S. Yanitsky, A.V. Gray, Bulletin of Kemguki 19, 82-97 (2012) 